\title{
How Management Accounting affect firm performance?
}

\author{
Yuan Zhou, ${ }^{1, a}$, QiYun Wei ${ }^{2, b}$ \\ ${ }^{1}$ School of Accounting JiLin University of Finance and Economics Changchun, China \\ ${ }^{2}$ School of Accounting JiLin University of Finance and Economics Changchun, China
}

\begin{abstract}
In China, managers use Management Accounting to manage their companies, so scholars have begun to study how Management Accounting will affect firm performance. According to the resource-based theory, this paper argues that Management Accounting will affect firm performance by influencing corporate innovation behavior. In order to verify this hypothesis, Management Accounting and controls, ambidextrous innovation (including exploratory innovation and exploitative innovation) and firm performance are tested by structural equation modeling with survey data from 188 companies in China. The research conclusion shows that the use of Management Accounting and controls can improve corporate performance, and ambidextrous innovation is an intermediary.
\end{abstract}

\section{INTRODUCTION}

With the globalization of the economy and industrial chain, Chinese companies are facing increasing pressure from competition. The managerial ability of managers has become a key factor in determining the success or failure of a company. As an important tool for managers to manage companies, Management Accounting has demonstrated its important role in management control. Many scholars have investigated the use of Management Accounting by Chinese companies, and the results show that Management Accounting and control technology are being used by more and more companies. It is widely known, the ultimate goal of Management Accounting is to help enterprises in their value creation activities. However, there is no clear mechanism for how Management Accounting can help companies create value. Previously, scholars studied the impact of single Management Accounting and controls on company performance, but ignored the effect of Management Accounting as a whole.

Management Accounting is a method for managers to manage a company, through the organization and coordination to achieve the integration and utilization of resources. In essence, the company's innovative behavior is also the integration and utilization of resources. Therefore, we believe that corporate innovation should be included in the research model of Management Accounting and company performance. Ambidextrous innovation theory classifies innovation into exploratory innovation and exploitative innovation. We assume that the degree of influence of Management Accounting on different innovative behaviors is different.

\section{LITERATURE REVIEW AND DEVELOPMENT OF THE HYPOTHESES}

\subsection{Relationship between Management Accounting and controls and firm performance}

Management Accounting improves the performance of firms from two aspects: providing information and management control. First of all, Management Accounting and controls can provide managers with the company's financial information and non-financial information, and help company managers make decisions. Eddy found that the activity cost information obtained through the activity-based costing method played a positive role in the managers' competitive pricing decisions [1]. Management Accounting and controls can provide information to employees and help improve employee efficiency, thereby improving firm performance. Through a survey of factory workers, Banker found that the implementation of Total Quality Management can provide employees with more production information [2]. Employees with more information have better job performance and are more willing to accept difficult jobs.

Secondly, Management Accounting and controls are important tools for managers to manage and control companies, and they play an important role in production, technology and organization. Through an empirical study, Ittner found that activity-based costing (ABC) can shorten the production cycle of products and improve product quality, thereby reducing product production costs and improving enterprise performance [2]. When Zengbiao $\mathrm{Yu}$ investigated Chinese companies, he found that when companies implement process management, they must rely on the management control function of the 
Management Accounting system to improve corporate performance. He considers that the management control functions include: goal setting, monitoring, and reward and punishment mechanisms combined with goals[2].

Through the above analysis, we consider that Management Accounting and controls can improve firm performance. We select financial performance and nonfinancial performance to comprehensively evaluate firm performance, and try to explore whether there are differences in the impact of Management Accounting.

Based on the above theoretical analysis, we put forward two hypotheses:

H1: Management Accounting and controls are positively related to financial performance.

H2: Management Accounting and controls are positively correlated with non-financial performance

\subsection{Relationship between Management Accounting and controls and Ambidextrous innovation}

Management Accounting and controls can provide necessary information for innovation behavior to improve Innovation performance. According to Davila, product innovation behavior has great uncertainty in development, technology, and market scope[3]. However, Management Accounting and control technology can provide managers with important information during the product development process and improve the company's innovation capabilities. Ambidextrous innovation includes exploratory innovation and exploitative innovation. Because of the different uncertainties they face, Management Accounting and control technology should provide different information. A case study Decoene and Bruggeman found that employees are more efficient if they know the financial results caused by their own actions[4]. This is crucial to the company's new product development.

Different Management Accounting and controls provide different Management Accounting information, which will affect the company's innovative behavior. Hitt found that if managers focus on objective and clear financial information, then rational employees will choose simpler jobs in order to avoid risks and reduce innovation; on the contrary, if managers pay more attention to more subjective information like customers Satisfaction, then managers are more inclined to encourage scientific researchers to innovate[5].

In addition, Management Accounting and controls can systematically evaluate different innovative solutions, and guide innovators to continuously propose new ideas, expand the scope of existing knowledge of the enterprise and stimulate innovation vitality. Through the above analysis, this article believes that Management Accounting tools can enhance the ambidextrous innovation of enterprises.

Based on the above theoretical analysis, we put forward two hypotheses:

H3: Management Accounting and controls are positively related to exploratory innovation.
H4: Management Accounting and controls are positively related to exploitative innovation.

\subsection{Relationship between Ambidextrous innovation and firm performance}

By integrating existing knowledge and resources, companies that carry out ambidextrous innovations have formed a unique competitive advantage, able to adapt to the uncertainty of the external environment, and thus have better performance[6]. However, based on the difference in nature, exploratory innovation and exploitative innovation have different effects on firm performance. On the one hand, exploratory innovation activities need to absorb external knowledge, pursue new technologies, and create new products and differentiated competitive advantages. Exploratory innovation requires enterprises to have strong knowledge absorption capacity, absorb the tacit knowledge in external technology and apply it to the innovation activities of the enterprise. Exploratory innovation has a low success rate and high risk, but once it succeeds, it will significantly improve corporate performance. On the other hand, exploitative innovation activities improve existing knowledge and technology, make existing products or services better, and thereby enhance corporate performance. The more exploitative innovations are carried out, the higher the efficiency of innovation and product improvement, and the higher the performance of the company. Exploitative innovation has a high success rate and low risk, but its effect on firm performance is not as good as exploratory innovation.

Based on the above theoretical analysis, we put forward four hypotheses:

H5: Exploratory innovation is positively related to a company's financial performance.

H6: Exploratory innovation is positively related to the non-financial performance of the company.

H7: Exploitative innovation is positively related to a company's financial performance.

H8: Exploitative innovation is positively related to the non-financial performance of the company.

\section{RESEARCH METHOD}

\subsection{Sample and data collection}

This article needs to study five variables: Management Accounting and controls, exploratory innovation, Exploitative innovation, financial performance and nonfinancial performance. Because they are latent variables, we need to use the questionnaire to collect sample data. In order to fully examine the impact of Management Accounting and control technology for the performance of the company, we do not limit the type of surveyed companies. But in order to ensure the accuracy of survey data, this study investigated the financial officers or senior managers. We have prepared a questionnaire on the website "questionnaire Star" and send a link to the participants. Research time from the beginning of April 2020 to the end of July 2020, we received a total of 188 
parts respondents. When we write the questionnaire, all items set must answer the question items, so no missing values in the sample data. In the end, we got 188 valid questionnaires.

\subsection{Measurement}

\subsubsection{Management Accounting and controls}

Referring to the papers of Sha Xiujuan and Pasch, we selected the most representative ones from all Management Accounting and controls as the measurement items of the scale. The 12 Management Accounting and controls we selected are: strategic map, value chain management, comprehensive budgeting, target costing, standard costing, activity-based costing, cost-volume-profit analysis, benchmarking, economic value-added, and balance Scorecard, total quality management, life cycle cost management. Factor analysis reveals one factor with composite reliability equals to 0.926 .

\subsubsection{Ambidextrous innovation}

Ambidextrous innovation includes exploratory innovation and exploitative innovation. Ambidextrous force of innovation is $\mathrm{Li}$ and Zhang $\mathrm{Yu}$ previously used scale, a total of 10 test items, including five exploratory invasive measurement items and 5 Exploitative innovative observation items. Factor analysis reveals one factor with composite reliability equals to 0.930 (exploratory innovation) and 0.926 (exploitative innovation)[7]

\subsubsection{Firm performance}

Firm performance includes financial performance and non-financial performance. There are five financial performance indicators: return on investment, cash flow from operating activities, product cost control, operating and management expense control, and sales revenue growth rate. The measurement indicators were previously used by Govindarajan \& Fisher and Bisbe \& Otley[8]. There are four non-financial performance indicators: market share, customer satisfaction, employee satisfaction, and the timeliness of providing products and services, which were previously used by Govindarajan \& Fisher and Xiao [9]. Non-financial performance is a formative model in PLS-SEM. Factor analysis reveals one factor with composite reliability equals to 0.940 . Non-financial performance is a formative model and does not test composite reliability.

\section{Results}

\subsection{Full latent model}

The full latent model based on the conceptual model depicted in Fig. 1 was estimated. The full latent model consists of both, the measurement and the structural models. The measurement model is concerned with the measurement properties of the instruments while the structural model is concerned with causal relationships among the constructs and their relative explanatory power.

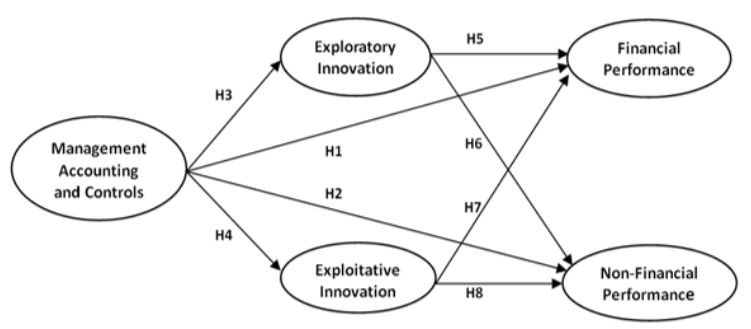

Figure 1 Conceptual model of the study

\subsection{Measurement model}

The measurement model of this study includes reflection model and formative model. Due to the existence of formative models, it is necessary to use PLS-SEM to analyze the data.

There are four reflective models: Management Accounting and controls, exploratory innovation, exploitative innovation and financial performance. We evaluate the validity of the measurement model from three aspects: individual item loadings, the composite reliability (CR), and the average variance extracted (AVE). The results show all items reach standardized loadings equal to or greater 0.719 , the squared root of AVE of all constructs is higher than 0.612 , the composite reliability is higher than 0.926. Discriminant validity is assessed through the Fornell-Larcker criterion [10]. The results show the square root of the average variance extracted (AVE) of each latent variable is greater than the correlation coefficient between it and other latent variables. Based on these results, we conclude that the measurement model has sufficient convergent and discriminant validity.

There are one reflective model, we need to check its weight value and whether there is a multi-collinearity problem. Multivariate collinearity is generally tested with the variance expansion factor VIF, and the VIF value should be less than 10 . The results show all items reach standardized weight between 0.173 and 0.342 , and VIF value is less than 2.961 .

\subsection{Structural model}

\subsubsection{Hypothesis testing}

The hypothesis are tested by parameter estimates calculated by the structural equation model. In this study, the Bootstrapping function in Smart PLS 3.0 was used to test the significance of each path coefficient. The sampling times were 5000 times. The results obtained are shown in Figure 2. First of all, consistent with H1, there is a direct and positive relationship between the Management Accounting and Controls and Financial 
Performance $(0.154, \mathrm{p}<0.05)$. But, the relationship between the Management Accounting and Controls and Non-Financial Performance is not significant $(0.062, \mathrm{p}>$ $0.10), \mathrm{H} 2$ are not supported. Second, consistent with H3 $(0.461, \mathrm{p}<0.01)$ and $\mathrm{H} 4(0.430, \mathrm{p}<0.01)$, Management Accounting and Controls is positively related to the Ambidextrous innovation. $\mathrm{H} 3$ and $\mathrm{H} 4$ are hence supported. Third, the relationship between the Exploratory Innovation and Financial Performance $(0.327, \mathrm{p}<0.01)$ and Non-Financial Performance $(0.306, p<0.01)$ are positive and significant. H5 and H6 are hence supported. The relationship between the Exploitative Innovation and Financial Performance $(0.313, \mathrm{p}<0.01)$ and NonFinancial Performance $(0.407, \mathrm{p}<0.001)$ are positive and significant. $\mathrm{H} 7$ and $\mathrm{H} 8$ are hence supported.

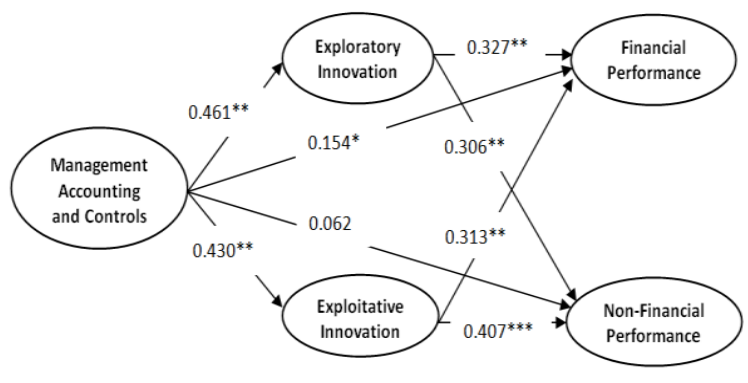

Figure 2 Direct and indirect paths

TABLE I. RESULTS OF A STRUCTURAL EQUATION MODEL (N 188)

\begin{tabular}{|c|c|c|c|c|}
\hline $\begin{array}{c}\text { Dependent } \\
\left.\text { variable( } \boldsymbol{R}^{2}\right)\end{array}$ & $\begin{array}{c}\text { Independent } \\
\text { variable }\end{array}$ & $\begin{array}{c}\text { Hypothe } \\
\text { sis }\end{array}$ & $\begin{array}{c}\text { Hypothe } \\
\text { sized } \\
\text { direction }\end{array}$ & $\begin{array}{c}\text { Base } \\
\text { model }\end{array}$ \\
\hline $\begin{array}{c}\text { Exploratory } \\
\text { Innovation } \\
(0.212)\end{array}$ & $\begin{array}{c}\text { Management } \\
\text { Accounting and } \\
\text { Controls }\end{array}$ & $\mathrm{H} 1$ & + & $0.154^{*}$ \\
\hline $\begin{array}{c}\text { Exploitative } \\
\text { Innovation } \\
(0.184)\end{array}$ & $\begin{array}{c}\text { Management } \\
\text { Accounting and } \\
\text { Controls }\end{array}$ & $\mathrm{H} 2$ & - & 0.062 \\
\hline $\begin{array}{c}\text { Financial } \\
\text { Performance } \\
(0.477)\end{array}$ & $\begin{array}{c}\text { Management } \\
\text { Accounting and } \\
\text { Controls }\end{array}$ & $\mathrm{H} 3$ & + & $0.461^{* *}$ \\
\hline $\begin{array}{c}\text { Non-Financial } \\
\text { Performance } \\
(0.498)\end{array}$ & $\begin{array}{c}\text { Management } \\
\text { Accounting and } \\
\text { Controls }\end{array}$ & $\mathrm{H} 4$ & + & $0.430^{* *}$ \\
\hline $\begin{array}{c}\text { Financial } \\
\text { Performance }\end{array}$ & $\begin{array}{c}\text { Exploratory } \\
\text { Innovation }\end{array}$ & $\mathrm{H} 5$ & + & $0.327^{* *}$ \\
\hline $\begin{array}{c}\text { Non-Financial } \\
\text { Performance }\end{array}$ & $\begin{array}{c}\text { Exploratory } \\
\text { Innovation }\end{array}$ & $\mathrm{H} 6$ & + & $0.306^{* *}$ \\
\hline $\begin{array}{c}\text { Financial } \\
\text { Performance }\end{array}$ & $\begin{array}{c}\text { Exploitative } \\
\text { Innovation }\end{array}$ & $\mathrm{H} 7$ & + & $0.313^{* *}$ \\
\hline $\begin{array}{c}\text { Non-Financial } \\
\text { Performance }\end{array}$ & $\begin{array}{c}\text { Exploitative } \\
\text { Innovation }\end{array}$ & $\mathrm{H} 8$ & + & $0.407^{* * *}$ \\
\hline
\end{tabular}

\subsection{2 $R^{2}$}

The main evaluation criterion of the PLS-SEM structural model is the coefficient of determination $R^{2} . R^{2}$ represents the explanatory ability of the internal dependent variable by the exogenous variable, and the value range depends on the research field. This study adopts the Chin standard, and considers that 0.19 is weak explanatory power, 0.333 is moderate explanatory power, and 0.67 or higher is significant explanatory power [11]. The test results are shown in table II. The R2 of the intermediary variable Exploratory Innovation in the structural model is 0.2123 , which is greater than 0.19 , indicating that the explanatory ability is weak. The $\mathrm{R}^{2}$ of another intermediary variable exploitative innovation is 0.1847 , which is less than 0.19 , but a study by HSU shows that the calculation based on the Component-Based SEM is generally lower than the value calculated by the Covariance-Based SEM[12]. Therefore, it can be inferred that its explanatory power can also reach the standard of weak explanatory power. The $\mathrm{R}^{2}$ of the two dependent variables, Financial Performance and Non-Financial Performance are 0.4772 and 0.4975 , both of which are greater than the 0.333 standard, reaching a moderate explanatory power.

\subsubsection{Effect size $f^{2}$}

Effect size $\mathrm{f}^{2}$ is the degree of influence of exogenous variables on endogenous variables, which is calculated by R2. In this study, the standard of Cohen was selected, f2 greater than 0.02 represents a weak effect, greater than 0.15 is a moderate effect, and greater than 0.35 is a strong effect[13]. The results show that the effect of Management Accounting and control technology on exploratory innovation and exploitative innovation is 0.2695 and 0.2265 , both of which are greater than 0.15 , which is a medium to high effect. Accounting Management and Control effect financial performance is 0.035 , larger than 0.02 , the effect is weak. The effect of Management Accounting and control technology on nonfinancial performance is 0.006 , which is less than 0.02 , indicating that its effect on non-financial performance is very small. The effect of exploratory innovation on financial performance and non-financial performance is 0.075 and 0.068 , both greater than 0.02 , and the effect is small to medium. The effect of exploitative innovation on financial performance and non-financial performance is 0.0709 and 0.1248 , both greater than 0.02 , and the impact is small to medium, and the impact of exploitative innovation on non-financial performance is stronger than its impact on financial performance.

\section{ConClusions AND DISCUSSION}

The purpose of this research is to explore how Management Accounting affects company performance, in which ambidextrous innovation is an intermediary variable. The results of the structural equation model show that Management Accounting can directly affect financial performance and indirectly affect non-financial performance through ambidextrous innovation. This finding is consistent with Management Accounting literature, indicating that Management Accounting can help enterprises in their value creation activities.

The limitation of this article is that this study sets a narrow focus, only investigating the intermediary effect of ambidextrous innovation.

\section{ACKNOWLEDGEMENT}

Csc and Jilin Education Department (JJKH20190735SK) 


\section{REFERENCES}

1. Eddy C. The value of activity-based costing in competitive pricing decisions[J]. Journal of Management Research, 2004:55-56.

2. Robert H. Chenhall,Frank Moers. The role of innovation in the evolution of Management Accounting and its integration into management control[J]. Elsevier Ltd,2015,47.

3. Shaker A. Zahra,Gerard George. Absorptive Capacity: A Review, Reconceptualization, and Extension[J]. Academy of Management,2002,27(2).

4. Barry A. Colbert. The Complex Resource-Based View: Implications for Theory and Practice in Strategic Human Resource Management[J]. Academy of Management,2004,29(3).

5. Michael A. Hitt,Robert E. Hoskisson,Richard A. Johnson,Douglas D. Moesel. The Market for Corporate Control and Firm Innovation[J]. Academy of Management,1996,39(5).

6. Valerie Decoene,Werner Bruggeman. Strategic alignment and middle-level managers' motivation in a balanced scorecard setting $[\mathrm{J}]$. Emerald Group Publishing Limited,2006,26(4).

7. Tony Davila. An empirical study on the drivers of management control systems' design in new product development[J]. Elsevier Ltd,2000,25(4).

8. Ying Li,Wim Vanhaverbeke,Wilfred Schoenmakers. Exploration and Exploitation in Innovation: Reframing the Interpretation[J]. Blackwell Publishing Ltd,2008, 17(2).

9. Zi-Lin He,Poh-Kam Wong. Exploration vs. Exploitation: An Empirical Test of the Ambidexterity Hypothesis[J]. INFORMS,2004,15(4).

10. Mary J. Benner,Michael L. Tushman. Exploitation, Exploration, and Process Management: The Productivity Dilemma Revisited[J]. Academy of Management,2003,28(2).

11. James G. March. Exploration and Exploitation in Organizational Learning[J]. Institute of Management Sciences, 1991,2(1).

12. Kaplan, R .S., and D.P.Norton.2001.Transforming the Balanced Scorecard from Performance Measurement to Strategic Management:Part II .Accounting Horizons, 15( 2):147-160.

13. Johnson,H.T., and Kaplan,R.S. Relevance Lost:The Rise and Fall of Management Accounting[M].Harvard Business School Press,Boston,Massachusetts, 1987. 